\title{
Using Red List species in designating protection status to forest areas: a case study on the problem of spatio-temporal dynamics
}

\section{Lise Tingstad ${ }^{1,2,3} \cdot$ John-Arvid Grytnes ${ }^{1} \cdot$ Magne Sætersdal $^{2} \cdot$ Ivar Gjerde $^{2}(\mathbb{D}$}

Received: 24 February 2020 / Revised: 27 July 2020 / Accepted: 5 August 2020 / Published online: 12 August 2020 (c) The Author(s) 2020

\begin{abstract}
Red-listed species are often used as target species in selection of sites for conservation. However, limitations to their use have been pointed out, and here we address the problem of expected high spatio-temporal dynamics of red-listed species. We used species data (vascular plants, bryophytes, macrolichens and polypore fungi) from two inventories 17 years apart to estimate temporal turnover of red-listed and non-red-listed species in two forest areas (147 and $195 \mathrm{ha}$ ) and of plots (0.25 ha) within each area. Furthermore, we investigated how turnover of species affected the rank order of plots regarding richness of red-listed species, using two different national Red List issues (1998 and 2015). In both study areas, temporal turnover was substantial, despite minor changes in the overall number of species. At plot level, temporal turnover in red-listed species was higher than in non-red-listed species, but similar to non-red-listed species of the same frequency of occurrence. Adding the effect of changing identities of species red-listed according to the two Red List issues, further increased the estimated spatio-temporal dynamics. Recorded spatio-temporal turnover also resulted in substantial changes in the rank order of plots regarding richness of red-listed species. Using rare red-listed species for site selection may therefore be accompanied by a higher loss of conservation effectiveness over time than for more common species, and particularly at finer scales.
\end{abstract}

Keywords Red-listed species $\cdot$ Site selection $\cdot$ Spatio-temporal dynamics $\cdot$ Temporal turnover

Communicated by Dirk Sven Schmeller.

Electronic supplementary material The online version of this article (https://doi.org/10.1007/s1053 1-020-02031-4) contains supplementary material, which is available to authorized users.

Ivar Gjerde

ivar.gjerde@nibio.no

1 Department of Biological Sciences, University of Bergen, Thormøhlensgate 54A, 5020 Bergen, Norway

2 Norwegian Institute of Bioeconomy Research (NIBIO), Thormøhlensgate 55, 5006 Bergen, Norway

3 Norwegian Institute for Nature Research, NINA, Høgskoleringen 9, 7034 Trondheim, Norway 


\section{Introduction}

One of the main tools for conservation of biological diversity is the selection and establishment of protected areas. The issue of selecting the most effective sites for this purpose has therefore gained much attention during the last decades (Kirkpatrick 1983; Butchart et al. 2015; Asaad et al. 2017). Various strategies and tools for site selection have been developed, both concerning target species data (e.g., Margules and Pressey 2000; Moilanen et al. 2009; Watson et al. 2011; Kukkula and Moilanen 2013; Lindenmayer et al. 2015), and establishment costs and other practical and societal issues (e.g., Naidoo et al. 2006; Runge et al. 2016).

Despite Red Lists primarily are designed to address extinction risk, the lists are frequently part of prioritization processes in selection of sites for conservation (Possingham et al. 2002; Eaton et al. 2005). Both global and national Red Lists (Gärdenfors et al. 2001; Baillie et al. 2004) are used for selection of sites for conservation (Ricketts et al. 2005; Rodrigues et al. 2006; Martín-López et al. 2011), and national Red Lists are among the most widely used tools at finer geographical scales (Schmeller et al. 2014). Two examples are the sites selected for the EU Habitat Directive (Henle et al. 2013) and the "Woodland Key Habitats" (WKH) in Northern Europe (Gustafsson et al. 1999; 2002; Gjerde et al. 2007; Hottola and Siitonen 2008).

Using Red List species as target species in conservation makes sense because they are by definition threatened or near threatened species, and using them for decision-making in conservation seem to have a high public acceptance (Lõhmus and Runnel 2018). However, this does not imply that occurrence data on red-listed species are ideal indicators of sites that should be prioritized for conservation. Several limitations to the use of red-listed species in site selection have been pointed out, most of them related to the fact that red-listed species usually are rare species:

(i) Prioritizing red-listed species may be a suboptimal strategy for minimizing extinction rates. By definition, red-listed species have an elevated risk of extinction, and they are often rare species (IUCN 2016). As it is well established that rare species are more prone to local extinctions (Gaston 1994; Margules et al. 1994; Rodrigues et al. 2000), prioritizing red-listed species may not be the most efficient way of minimizing extinction rates (Possingham et al. 2002). It has also been suggested that the well-being of common species may be more important for overall biodiversity conservation (Gaston 2010; Inger et al. 2015; Jansen et al. 2019).

(ii) Evaluation of threat depends on spatial scale. Conservation planning at the national scale tends to encompass only part of the distribution range of species (Rodrigues and Gaston 2002). Many nationally evaluated species are red-listed because they are rare at the edge of their natural distribution range (Gustafsson et al. 1999; Tingstad et al. 2017), and threat status at the national level may not reflect threat status in the entirety of its range and therefore does not always reflect actual conservation needs (Eaton et al. 2005; Schmeller et al. 2014).

(iii) Shortage of data undermines robustness of decisions based on known occurrences (Lõhmus and Runnel 2018). Because most red-listed species are rare and tiny, they are also difficult to detect. As a result, sufficient surveys of such species may become so demanding and expensive that they are rejected as impractical (Maes et al. 2011).

(iv) Species composition of Red Lists changes over time due to regular revisions. With each new edition of the Red List, some species are delisted, while others are enlisted, 
meaning that prior target species may be replaced by others. Such changes may erode the efficiency of sites selected to protect red-listed species according to a particular Red List issue (Gjerde et al. 2018).

In addition to the limitation pointed out above, the problem of spatio-temporal dynamics of species should be addressed. The identification of areas of high conservation value based on the occurrence of target species is commonly based on snapshots in time (Margules et al. 1994), as data on temporal variability in most cases are not available (Virolainen et al. 1999; Magurran et al. 2010; Felinks et al. 2011). Temporal changes in distribution patterns can therefore be a real challenge, as reserve sites or networks may not continue to serve their original purpose if target species have a high rate of spatio-temporal dynamics (Margules et al. 1994; Virolainen et al. 1999; Rodrigues et al. 2000). As red-listed species are rare and threatened species one would expect them to experience higher spatio-temporal dynamics than non-red-listed species. In a conservation context it is important to take into consideration the degree of dynamics of target species, and to our knowledge no study has yet measured the spatio-temporal dynamics of red-listed species at finer scales and the implications for using them in fine-scale site selection.

In a case study we investigated the effect of spatio-temporal dynamics on conservation values based on red-listed species. We used species occurrence data from two inventories conducted in 1997-1998 and 2014-2015 in two protected forest areas in Norway. Species dynamics was investigated at two different spatial scales, relevant for identifying small reserves and "Woodland Key Habitats", respectively. We pooled species data from four organism groups to obtain a multi-taxa sample; bryophytes, macrolichens, polypore fungi, and vascular plants. The protected status of the study areas allowed us to study species dynamics in forested areas where local anthropogenic disturbances have had a minimal impact on species in the 17-year period between the two inventories.

The main aims of this study were (1) to estimate spatio-temporal dynamics of red-listed species and non-red-listed species in the two forest areas and, and (2) to investigate how this dynamics in red-listed species translates into changes in the rank order of sites regarding conservation values measured as richness of red-listed species at the finer scale. In addition, we added the effect of changing Red List species composition to extend the picture of dynamics experienced when using red-listed species as target species in conservation. We discuss how high spatio-temporal dynamics may have consequences for the effectiveness of conservation sites over time, and how Red List species may be used as target species without using them directly in site selection.

\section{Materials and methods}

\section{Study areas}

The two study areas were originally chosen to represent hemi-boreal forest in Western Norway and boreal forest in Eastern Norway, and constitute 147 and 195 ha, respectively. Each area covers large internal variation in environmental characteristics including slope, aspect, vegetation type, age of trees and the amount of dead wood.

The Kvam study area is situated on the west coast of Norway $\left(60^{\circ} \mathrm{N}, 5^{\circ} \mathrm{E}\right)$. It has an oceanic climate with mean annual temperature of $7.2{ }^{\circ} \mathrm{C}$ and a mean annual precipitation of $2600 \mathrm{~mm}$, following the normal period 1961-1990 (Aune 1993; Førland 1993). 
Semi-natural coniferous forest (naturally regenerated forest including trees older than 100 years) is the dominant forest type and the tree species assemblage is largely dominated by Pinus sylvestris. In addition, broad-leaved deciduous forest with Fraxinus excelsior, Alnus incana, Tilia cordata, and Ulmus glabra comprises about $11 \%$ of the area. The area has been protected as a nature reserve since 1997. The last 50 years prior to reserve establishment, cutting of trees or other forms of human disturbance were negligible (Gjerde et al. 2005).

The Sigdal study area is situated inland in southeast Norway $\left(60^{\circ} \mathrm{N}, 9^{\circ} \mathrm{E}\right)$. It has a more continental climate than Kvam, with mean annual temperature of $3.7^{\circ} \mathrm{C}$ and a mean annual precipitation of $800 \mathrm{~mm}$, following the normal period from 1961-1990 (Aune 1993; Førland 1993). The area is dominated by flat areas with $P$. sylvestris stands interspersed by bogs, and slopes dominated by stands of Picea abies. The coniferous forest contains a varying amount of the boreal deciduous tree species Betula pubescens, Populus tremula, Sorbus aucaria and Salix caprea. The study area is part of a nature reserve established in 2002. The area is dominated by semi-natural forest, but also includes planted $P$. abies and $P$. sylvestris stands. As in the Kvam study area, there are few signs of recent cutting of trees in the semi-natural stands. More ancient historical impact includes prescribed burning and dairy farming (Gjerde et al. 2005; Rolstad et al. 2017).

\section{Species inventories}

In 2014 and 2015, species inventories were carried out in the Kvam and Sigdal study areas, respectively. These inventories were repetition of earlier inventories in these areas performed in 1997 and 1998 (Gjerde et al. 2004, 2005), separating the two inventories by 17 years in both areas. At the first inventory in 1997-98, each study area was divided into a grid composed of 1 ha grid cells; 147 grid cells in Kvam, and 195 grid cells in Sigdal. A smaller sample plot of $50 \times 50 \mathrm{~m}(0.25 \mathrm{ha})$ was established in the southeast corner of each grid cell (Supplementary material Fig S1). In 2014-15, a re-inventory was performed in 40 randomly selected plots in each area, stratified on main forest types to assure representative samples. The plots were re-located using a map with grid cells from which the southeast corner in each plot could be identified by permanent markings and terrain characteristics from detailed maps. We re-established the plot by using $50 \mathrm{~m}$ measuring tape and compass courses starting at the southeast corner. Plot corners were marked with coloured bands and GPS positions were recorded.

Occurrences of species of bryophytes (Kvam study area only), macrolichens, polypore fungi and vascular plants were recorded in sample plots. Vascular plants were recorded at all substrates, macrolichens and bryophytes on logs, rocks, bare soil, as well as trees, snags and rock walls below $2 \mathrm{~m}$. Fruiting bodies of polypore fungi were recorded on logs, snags and standing trees. Experts were instructed to carry out exhaustive species search, and the time of field inventory depended on the time needed for species records to level off ( $0.5-8 \mathrm{~h}$ per plot, depending on species group and plot). The second inventory followed the procedures from the first inventory, and effort was made to perform it the exact same way. Exhaustive species search was carried out, and presence or absence was recorded for species within the same organism groups. Most specimens were identified in the field and the rest were collected for identification in the laboratory. In most cases the same surveyors performed the registrations at both inventories, or new surveyors that participated at the second inventory received field training from the former surveyors prior to the inventory. 
However, for vascular plants inventory effort was higher in the second inventory as it was conducted by two observers in each plot.

The term "red-listed" here refers to species in the Norwegian national Red List completed in 1998 (Direktoratet for naturforvaltning 1999) in the categories "declining, monitor species" (DM), "declining, care demanding" (DC), "rare" (R), "vulnerable" (V) and "endangered" (E), and from the Norwegian Red List for species 2015 (Henriksen and Hilmo 2015) in the categories "data deficient" (DD), "near threatened" (NT), vulnerable" (VU), "endangered" (EN), and "critically endangered" (CR) following IUCN's criteria and guidelines version 3.1 (IUCN 2012). The Norwegian Red List for species (Henriksen and Hilmo 2015) includes species listed with "data deficiency" as red-listed species, and we therefore include these species here. Below, the two Red Lists are referred to as RL98 and RL15, respectively.

\section{Analyses}

Spatio-temporal dynamics of species may result in changes in both species richness and in spatial distribution of species in an area over time. Accordingly, the comparison of spatiotemporal dynamics of red-listed and non-red-listed species between the first and second inventory included both estimation of changes in the number of species recorded and estimation of temporal turnover in species composition at sites for both spatial scales. Temporal turnover is here defined as changes in species composition over time within a study area or within a plot between the first and second inventory, based on presence-absence data. We

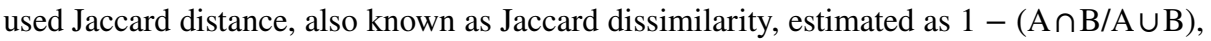
where A and B represent two sets of species compared (Levandowski and Winter 1971). The index ranges from 0 to 1 , where a Jaccard distance of 1 corresponds to a total turnover in species, and 0 corresponds to equal composition.

We estimated temporal turnover of red-listed species at the study area level $(n=2)$ and at the plot level $(\mathrm{n}=40$ for each study area). At the study area level, temporal turnover was measured as Jaccard distance between the set of species recorded in the two inventories and was based on species lists combining records from all plots. We used both RL98 (Direktoratet for naturforvaltning 1999) and RL15 (Henriksen and Hilmo 2015) in separate comparisons, as the pattern of occupancy might change with different editions of the Red List (Gjerde et al. 2018). At the plot level, the estimation of turnover was based on calculation of Jaccard distance for each plot with occurrences of red-listed species in the first, second, or both inventories, following either RL98 or RL15. The mean Jaccard distance estimated for the plot level is hereafter referred to as turnover at plot level.

Turnover of red-listed species was compared to the corresponding turnover for the nonred-listed species. Because turnover of species may be affected by their frequency of occurrence (Latombe et al. 2018), and red-listed species tend to be rarer than non-red-listed species, estimated temporal turnover for the two groups would not be directly comparable. In order to address this issue in the analysis, we randomly selected a set of non-red-listed species with the same frequency of occurrence (number of plots where the species were recorded) as for the red-listed species. This allowed us to compare temporal turnover for both red-listed and non-red-listed species in general, and for red-listed and non-red-listed species with the same frequency of occurrence. For simplicity the selected non-red-listed species are hereafter referred to as "sister species". The selection of sister species was run 999 times with a random selection of species with the same frequencies of occurrences as the red-listed species in each permutation. The number of cases where the sister species 
showed a higher or equal (or lower or equal) turnover compared to the red-listed species was counted and divided by 1000 (iterations plus the recorded turnover). This is a twosided test, and the significance level was therefore set to 0.025 .

We also included the changes in the identity of red-listed species from RL98 to RL15 (Gjerde et al. 2018) for an estimation of the total rate of spatio-temporal dynamics caused by the combination the observed temporal turnover of species, and the changes in target species caused by Red List updates. This combination was estimated with Jaccard distance, when using the RL98 for the species recorded in the first inventory and RL15 for the second inventory (from a to $\mathrm{d}$ in Fig. 1).

Neither changes in target species identity nor temporal turnover necessarily change the importance or rank order of sites selected for conservation. Turnover might be high also in cases where the relative value of sites remains the same. Here we focused on the rank order of sites regarding richness of target species. We therefore investigated to what degree temporal turnover and changes in target species resulted in changes in the rank order of plots regarding their richness of red-listed species. The degree of changes in rank was estimated by calculating the Kendall's rank correlation coefficient based on the number of redlisted species in the plots at the two inventories using RL98, and when adding the effect of changing from RL98 to RL15 (i.e., from a to $b$ and from a to d in Fig. 1).

All calculations were performed in R version 3.6.1 ( $\mathrm{R}$ Core Team 2019).

\section{Results}

\section{Number of species}

Within and among study areas, the total number of species recorded was nearly identical at the two inventories (Table 1). Species were almost exclusively (>99\%) native forest species. Red-listed species comprised between 1.8 and 2.3\% in Kvam and between 4.9 and $7.1 \%$ in Sigdal, depending on inventory and Red List used. The highest number of redlisted species was found using RL15 in both areas and inventories (Table 1). At the plot level, the mean number of red-listed species tended to increase from inventory 1 to inventory 2 .

Fig. 1 Four lists of recorded red-listed species used in the analysis (a-d), based on the combinations of two different inventories and two different Red List issues. Jaccard distance was used to measure changes in species composition as a result of temporal turnover using each of the Red Lists RL98 and RL15 (from $\mathbf{a}$ to $\mathbf{b}$ and from $\mathbf{c}$ to $\mathbf{d}$ ), to measure changes due to Red List updates for inventory 1 (from a to c), and finally to measure the changes when combining the two components (from a to d)

\section{Inventory 1 Inventory 2}

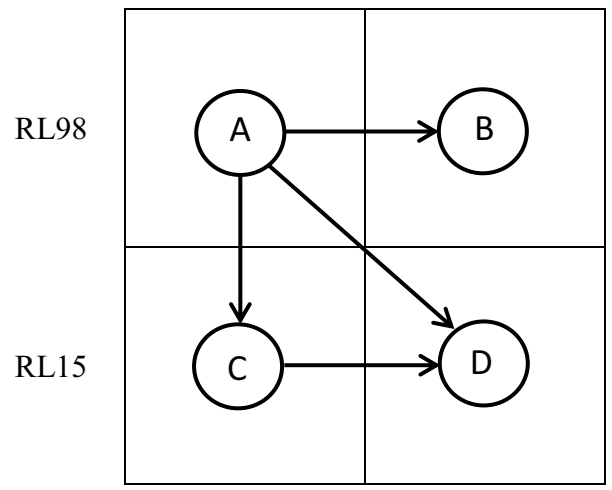


Table 1 Number of all species and red-listed species recorded in study areas Kvam and Sigdal, and mean number $( \pm 2 \mathrm{SE})$ of all species and red-listed species found in sample plots at the two inventories (Inv $1=$ inventory $1997-98$, Inv 2 = inventory 2014-15)

\begin{tabular}{|c|c|c|c|c|c|c|}
\hline & \multicolumn{2}{|l|}{ All species ${ }^{\mathrm{a}}$} & \multicolumn{2}{|l|}{ RL98 } & \multicolumn{2}{|l|}{ RL15 } \\
\hline & Inv 1 & Inv 2 & Inv 1 & Inv 2 & Inv 1 & $\operatorname{Inv} 2$ \\
\hline \multicolumn{7}{|l|}{ Kvam } \\
\hline Whole study area & 655 & 654 & 12 & 13 & 15 & 15 \\
\hline $\begin{array}{l}\text { Mean no./plot } \\
\text { Sigdal }\end{array}$ & $170.7( \pm 15.08)$ & $180.6( \pm 16.72)$ & $0.6( \pm 0.35)$ & $1.0( \pm 0.48)$ & $1.6( \pm 0.69)$ & $2.3( \pm 0.82)$ \\
\hline Whole study area & 241 & 243 & 14 & 12 & 17 & 15 \\
\hline Mean no./plot & $64.6( \pm 5.08)$ & $66.9( \pm 5.18)$ & $1.4( \pm 0.50)$ & $2.8( \pm 0.49)$ & $1.7( \pm 0.52)$ & $3.0( \pm 0.49)$ \\
\hline
\end{tabular}

Red-listed species followed Red List 1998 (RL98) and Red List 2015 (RL15), respectively

${ }^{a}$ Kvam: vascular plants, bryophytes, macrolichens, and polypore fungi; Sigdal: vascular plants, macrolichens, and polypore fungi

The lower overall number of species recorded in Sigdal compared to Kvam was partly because bryophytes were not included in the Sigdal inventory, and partly because Kvam contained species-rich broad-leaved forest. For a list of all red-listed species recorded at each inventory, see Supplementary material Table S1.

The number of plots (out of 40) with occurrences of red-listed species in Kvam increased from inventory 1 (RL98: 13 plots, RL15: 21 plots) to inventory 2 (RL98: 19 plots, RL 15: 29 plots). In Sigdal the number of plots with red-listed species did not show a particular trend from inventory 1 (RL98: 24 plots, RL15: 39 plots) to inventory 2 (RL98: 26 plots, RL15: 36 plots). The number of plots with red-listed species increased when shifting from RL98 to RL15 in both areas and for both inventories.

\section{Temporal turnover}

Although the number of all species recorded was similar in the two inventories, a pronounced temporal turnover in species composition was found at both spatial scales and in both study areas.

For species on RL98, temporal turnover at plot level was estimated to a mean Jaccard distance of 0.86 in Kvam and 0.77 for Sigdal, and for species red-listed in RL15 a lower Jaccard distance (0.68 and 0.52, respectively) was found for both areas (Table 2).

When comparing temporal turnover estimated for red-listed and non-red-listed species, a clearly higher turnover was found for red-listed species, both at area level and plot level, and when using either RL98 or RL15 for red-listed species (Table 2). However, when adjusting for frequency (comparing red-listed species and the sister species), temporal turnover of red-listed species did not differ significantly from the estimated temporal turnover of the sister species, except for Sigdal when using RL15 (Table 2).

\section{The effects of Red List updates}

The changes in red-listed species according to RL98 and RL15 resulted in six species no longer red-listed and nine new red-listed species in Kvam. In Sigdal, three species were 
Table 2 Temporal turnover (Jaccard distance) between the first and the second inventory, estimated for red-listed and non-red-listed species at the study area level and plot level, following Red List 1998 (RL98) and Red List 2015 (RL15) in Kvam and Sigdal study areas

\begin{tabular}{llllll}
\hline & \multicolumn{2}{l}{ Kvam } & & & \multicolumn{2}{l}{ Sigdal } \\
\cline { 6 - 6 } \cline { 5 - 6 } & RL98 & RL15 & & RL98 & RL15 \\
\hline Study area level & & & & \\
Non-red-listed species & 0.17 & 0.17 & & 0.27 & 0.26 \\
Red-listed species & 0.56 & 0.47 & 0.44 & 0.52 \\
Non-red-listed sister species & 0.52 & 0.37 & & 0.33 & $0.33^{* *}$ \\
Sample plot level & & & & \\
Non-red-listed species & 0.43 & 0.43 & & 0.36 & 0.37 \\
Red-listed species & 0.86 & 0.68 & & 0.77 & 0.52 \\
Non-red-listed sister species & 0.81 & 0.68 & 0.69 & $0.40^{* *}$ \\
\hline
\end{tabular}

The "sister species" represent non-red-listed species of the same frequency of occurrence as the red-listed species

${ }^{* *}$ Significantly different from turnover of red-listed species, $\mathrm{p}<0.01$

no longer red-listed and eight new species were added to the list. The effects of compositional changes in the Red List from RL98 to RL15 alone, led to an estimated mean Jaccard distance of 0.77 in Kvam and 0.85 in Sigdal for the red-listed species recorded at the first inventory (Table 3). The high Jaccard values recorded was partly because species added to the RL15 (not on RL98) often had a high mean frequency of occurrence, resulting in numerous new plots occupied by red-listed species.

When combining temporal turnover and compositional changes in the Red List, the result was an almost complete shift in species composition at the plot level between the two inventories, with mean Jaccard distances of 0.92 for both Kvam and Sigdal (Table 3).

\section{Species richness rank order}

The change in species occupancy of plots was accompanied by a change in the rank order of plots regarding richness of red-listed species. In Kvam, the maximum change in numerical rank order of plots was from rank 21.5 (0 RL-species) when using RL98 in inventory 1, to rank 6.5 (5 RL-species) using RL15 in inventory 2, and from 1 to 9 RL-species (Fig. 2b). In Sigdal, the maximum change in rank was also found when using RL98 in inventory 1 and RL15 in inventory 2, but with an opposite direction of change (from rank 1 to rank 28 and from 7 to 2-RL species) (Fig. 2d). The overall changes in ranks were reflected in the Kendall's

Table 3 Mean changes in composition of red-listed species (Jaccard distance) at plot level when (a) regarding only changes caused by shift from Red List 1998 (RL98) to Red List 2015 (RL15), and (b) when combining the Red List shift and temporal turnover

\begin{tabular}{lll}
\hline Area & Cause of change & Jaccard distance (n) \\
\hline Kvam & (a) Shift from RL98 to RL15 only & $0.77(22)$ \\
& (b) Combining Red List shift and temporal turnover & $0.92(30)$ \\
Sigdal & (a) Shift from RL98 to RL15 only & $0.85(39)$ \\
& (b) Combining Red List shift and temporal turnover & $0.92(40)$ \\
\hline
\end{tabular}

Changes are expressed as mean Jaccard distance at plot level. The number of plot pairs included (n) is given in brackets 

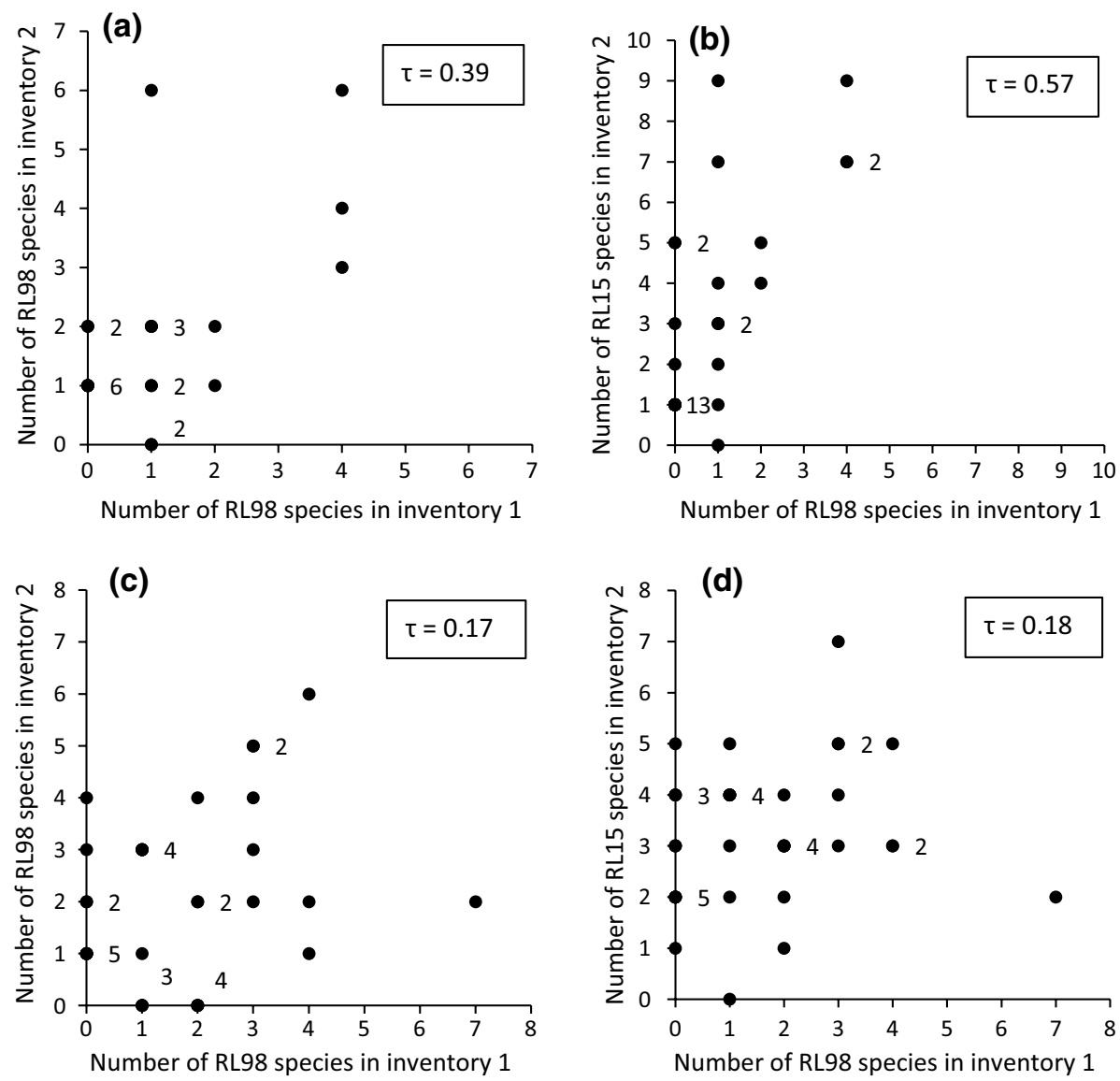

Fig. 2 The relationships between the number of red-listed species recorded in plots when a using RL98 in Kvam for both inventory 1 and 2, b when using RL98 at inventory 1 and using RL15 at inventory 2 in Kvam, c when using RL98 in both inventory 1 and 2 in Sigdal, and using RL98 at inventory 1 and using RL15 at inventory 2 in Sigdal. Numbers on the right hand side of dots indicate the number of plots with identical values for that particular value. $\tau$ gives the Kandall rank coefficient for the four relationships

rank correlation coefficient with lower correlation between first and second inventories in Sigdal compared to Kvam (Fig. 2). Kendall's rank correlation coefficient for richness of nonred-listed species was higher than for red-listed species ( 0.73 and 0.59 in Kvam and Sigdal, respectively), indicating a more stable species richness for non-red-listed species than for red-listed species. Although adding the effect of changing Red Lists increased the numerical change in rank among the highest-ranking plots in both areas, it did not result in a lower overall rank correlation coefficient (Fig. 2). 


\section{Discussion}

\section{Turnover patterns}

Recent studies have demonstrated that species assemblages can change considerably over a time period of years to decades (Parody et al. 2001; Chaideftou et al. 2012; Diekmann et al. 2014). Our multi-taxa species inventories in two northern forest reserve areas, conducted 17 years apart, agree with these results. Furthermore, we found that Red-listed species showed a consistently higher temporal turnover as compared to non-red-listed species, but not when compared with non-red-listed species of similar frequencies as red-listed species. Therefore, the higher turnover of red-listed species in our study does not seem to be primarily related to their threat status, but to their generally low frequency of occurrence.

According to the species pool theory of Zobel (1997), referred to as "regional replacement" in McGill and Nekola (2010), the abundances of species within a local community are controlled by regional replacement from a regional species pool. Red-listed species (and other species with low frequency of occurrence) may therefore have a higher temporal turnover than other species within a site simply because they have lower probability of colonizing the same site after extinction.

Temporal species turnover has in most cases been found to increase with decreasing spatial scale (Rodrigues et al. 2000; Adler et al. 2005; Chaideftou et al. 2012). In accordance with this, temporal turnover in both our study areas was higher at the sample plot scale compared to the study area scale, for both red-listed and non-red-listed species. As estimated temporal turnover at study area level was based on data from the sample plot level, we were able to track the changes from plot to area level. The reduction in temporal turnover at area level resulted from species extinctions at the sample plot level being compensated by survival and colonization in other plots. An exception was found in Sigdal (using RL15), where estimated temporal turnover for red-listed species was similar to that on plot level. In that case the presence of a few frequent red-listed species found in both inventories lowered the mean temporal turnover at the sample plot level.

Interpreting results from resampling studies should be done with caution. In all field inventories, inventory bias might affect the results. Estimates of indices of similarity based on presence-absence data are sensitive to sampling effort (Engen et al. 2011), and especially if the assemblage contains numerous rare species (Chao et al. 2005). Resampling studies may be subject to three types of errors: relocation errors, seasonality errors and observer errors (Kapfer et al. 2017; Verheyen et al. 2018). We consider relocation errors to be limited in this study as the plots were identified using permanent markings and terrain characteristics from detailed field maps. Seasonality errors are particularly relevant for the sampling of fungi as it is well known that amount of fruiting bodies of fungi vary considerably between years (Berglund et al. 2005). Observer error arises both because of different observers, as well as differences in time spent surveying in each plot between the two surveys (Archaux et al. 2006; Burg et al. 2015). The percentage of species found by one observer but not by another (i.e. pseudo-turnover) (Nilsson and Nilsson 1985) has been reported to be in the order of 10-30\% of the recorded turnover (Morrison 2016). Despite our efforts to minimize inventory errors to the lower part of the error range above, it is likely that our results include some pseudo-turnover as a result of different observers and different efforts in the two surveys. However, it should be noted that observer errors in our data are much lower to that of species data usually available for site selection in conservation. 
The small changes in species richness of study areas and individual plots, and the considerable level of temporal turnover are in accordance with several recent studies that have documented resilient species alpha-diversity and total abundance at the same time as consistent high temporal beta-diversity (Dornelas et al. 2014, 2019; Gotelli et al. 2017; Magurran et al. 2018). As a case study, our results may suffer from some local conditions or choice of taxa that may not readily be generalized. However, we consider the finding that red-listed species, due to their rareness, had a higher temporal turnover than other species, to be an important result. This result may be of general relevance for nationally red-listed species at similar scales in other countries because it is rooted in general patterns of species abundance distribution.

\section{Implications for conservation}

Spatio-temporal dynamics of target species and using selection strategies based on static species distributions derived from single year data, can easily lead to insufficient representation of species over time (Runge et al. 2016; Tulloch et al. 2016). Understanding dynamics in species distributions and how it may affect defined conservation values is therefore of key importance for long-term conservation planning.

We hypothesized that using red-listed species as target species in site selection will enhance the challenges associated with spatio-temporal dynamics, due to the threatened status and rareness of these species. Our case study demonstrated that high species temporal turnover of rare species lead to a situation where sites selected based on initial richness of red-listed species did not sustain these numbers over time. In addition to the effects of species temporal turnover, the compositional changes in the Red List due to revisions may also contribute to the dynamics experienced if red-listed species are used as target species for site selection. National Red Lists are frequently updated, and with each update some species are removed, and some are added. Gjerde et al. (2018) investigated how compositional changes in the Red List affected target species distribution at plot level and the consequences of these changes for site selection, and found that sites in boreal forest selected based on an older version of the Red List captured a lower proportion of red-listed species of the latest Red List 2015. In the present study, we have shown how the combination of temporal turnover and the changes in Red List composition due to updates gives an estimate of almost complete turnover of target species at sample plot level (Jaccard distance $>0.9$ ) in our two forest sites.

A high temporal turnover of species does not necessarily affect species richness or the differences in species richness between sites. For instance, sites in forest types that differ substantially in their capacity for species richness, including target species, may largely retain their relative rank order regarding species richness, despite high species turnover (Gjerde et al. 2018). For sites within in the same habitat type, however, the rank order of plots regarding richness of target species may be more susceptible to temporal turnover. That was the case for our $50 \times 50 \mathrm{~m}$ sample plots in the boreal forests of Sigdal, where the change in rank regarding richness of red-listed species was particularly high. Selecting plots based on richness of red-listed species would give a largely different set of plots in 2015 as compared to 1998.

Forecasting changes in biodiversity of species over time is essential for developing successful conservation plans to mitigate biodiversity loss (Dornelas et al. 2013), and may work well for climate change scenarios, or other long-lasting environmental trends. The population effects of stochasticity, however, are more difficult to implement in conservation 
decisions (Melbourne and Hastings 2008). Whereas demographic stochasticity results from chance events of individual mortality and birth causing population fluctuations primarily in small populations, environmental stochasticity causes populations of all sizes to fluctuate randomly (Lande et al. 2003). As our study was performed in nature reserves where direct impact from human activities were low, and within a time frame of 17 years, observed species dynamics may be attributed mainly to demographic and environmental stochasticity. In such cases, spatio-temporal dynamics might affect future distribution of target species in a rather unpredictable way and may cause the initial effectiveness of sites in hosting species for conservation to deteriorate over time (Magurran et al. 2010).

High spatio-temporal turnover in rare species, together with other limitations associated with rareness, challenge the possibilities to predict future distribution of red-listed species, and particularly at finer spatial scales. A better understanding of spatio-temporal dynamics, which may contribute to partitioning stochastic factors from predictable trends, has the potential to improve strategies for site selection. Even so, our results suggest that a moderate expectancy to the effectiveness of fine-scale set-asides selected based on occurrences of red-listed target species is warranted. Thus, instead of using dynamic positions of red-listed species in fine-scale site selection, one alternative strategy would be to use species-habitat data to designate important habitat types for each red-listed species (e.g., Leathwick et al. 2010; Moilanen 2012; Lindenmayer et al. 2015). This approach will not escape the challenge of spatio-temporal dynamics of species, but sites will be selected based on documented long-term association between habitat types and species, and not on a snapshot distribution of species. Then red-listed species will still be target species, but the specific species present at a certain site at a certain point in time is of secondary importance.

Acknowledgements We gratefully acknowledge the help of the species experts involved in the two species inventories in 1997-98 and in 2014-15, and the post inventory species identification: O. Aas, T. Bjelland, H. H. Blom, G. Gaarder, Y. Gauslaa, T. Høitomt, H. Holien, P. G. Ihlen, A. Lie, M. U. Maurset, E. Rolstad, I. Røsberg, L. Ryvarden, F. H. Schei, and A. Wrinckler. This research did not receive any specific grant from funding agencies in the public, commercial, or not-for-profit sectors.

Funding Open Access funding provided by Norwegian Institute of Bioeconomy Research.

Open Access This article is licensed under a Creative Commons Attribution 4.0 International License, which permits use, sharing, adaptation, distribution and reproduction in any medium or format, as long as you give appropriate credit to the original author(s) and the source, provide a link to the Creative Commons licence, and indicate if changes were made. The images or other third party material in this article are included in the article's Creative Commons licence, unless indicated otherwise in a credit line to the material. If material is not included in the article's Creative Commons licence and your intended use is not permitted by statutory regulation or exceeds the permitted use, you will need to obtain permission directly from the copyright holder. To view a copy of this licence, visit http://creativecommons.org/licenses/by/4.0/.

\section{References}

Adler PB, White EP, Lauenroth WK, Kaufman DM, Rassweiler A, Rusak JA (2005) Evidence for a general species-time-area relationship. Ecology 86:2032-2039

Archaux F, Gosselin F, Bergès L, Chevalier R (2006) Effects of sampling time, species richness and observer on the exhaustiveness of plant censuses. J Veg Sci 17:299-306

Asaad I, Lundquist CJ, Erdmann MV, Costello MJ (2017) Ecological criteria to identify areas for biodiversity conservation. Biol Conserv 213:309-316

Aune B (1993) Air temperature normals, normal period 1961-1990. Det norske metereologiske institutt, Klima 
Baillie J, Hilton-Taylor C, Stuart SN (2004) 2004 IUCN red list of threatened species: a global species assessment. IUCN, Gland

Berglund H, Edman M, Ericson L (2005) Temporal variation of wood-fungi diversity in boreal old-growth forests: implications for monitoring. Ecol Appl 15:970-982

Burg S, Rixen C, Stöckli V, Wipf S (2015) Observation bias and its causes in botanical surveys on highalpine summits. J Veg Sci 26:191-200

Butchart SHM, Clarke M, Smith RJ et al (2015) Shortfalls and solutions for meeting national and global conservation area targets. Conserv Lett 8:329-337

Chaideftou E, Kallimanis AS, Bergmeier E, Dimipoulus P (2012) How does plant species composition change from year to year? A case study from the herbaceous layer of a submediterranean oak woodland. Community Ecol 13:88-96

Chao A, Chazdon RL, Colwell RK, Shen T-J (2005) A new statistical approach for assessing similarity of species composition with incidence and abundance data. Ecol Lett 8:148-159

Diekmann M, Jandt U, Alard D, Bleeker A, Corcket E, Gowing DJG, Stevens CJ, Duprè C (2014) Longterm changes in calcareous grassland vegetation in North-western Germany-no decline in species richness, but a shift in species composition. Biol Conserv 172:170-179

Direktoratet for Naturforvaltning (1999) Norwegian Red List DN report. Norwegian Red List 1998

Dornelas M, Magurran AE, Buckland ST, Chao A, Chazdon RL, Colwell RK, Curtis T, Gaston KJ, Gotelli NJ, Kosnik MA, McGill B, McCune JL, Morlon H, Mumby PJ, Øvreås L, Studeny A, Vellend M (2013) Quantifying temporal change in biodiversity: challenges and opportunities. Proc R Soc B 280:20121931. https://doi.org/10.1098/rspb.2012.1931

Dornelas M, Gotelli NJ, McGill B, Shimadzu H, Moyes F, Sievers C, Magurran AE (2014) Assemblage time series reveal biodiversity change but not systematic loss. Science 344:296-299

Dornelas M, Gotelli NJ, Shimadzu H, Moyes F, Magurran AE, McGill BJ (2019) A balance of winners and losers in the Anthropocene. Ecol Lett 22:847-854

Eaton M, Gregory R, Noble D, Robinson J, Hughes J, Procter D, Brown A, Gibbons D (2005) Regional IUCN red listing: the process as applied to birds in the United Kingdom. Conserv Biol 19:1557-1570

Engen S, Grøtan V, Sæther B-E (2011) Estimating similarity of communities: a parametric approach to spatio-temporal analysis of species diversity. Ecography 34:220-231

Felinks B, Pardini R, Dixo M, Follner K, Metzger JP, Henle K (2011) Effects of species turnover on reserve site selection in a fragmented landscape. Biodivers Conserv 20:1057-1072

Førland EJ (1993) Precipitation normals, normal period 1961-1990. Det norske metereologiske institutt, Klima

Gaston KJ (1994) Rarity. Springer, Netherlands

Gaston KJ (2010) Valuing common species. Science 327:154-155

Gjerde I, Sætersdal M, Rolstad J, Blom HH, Storaunet KO (2004) Fine-scale diversity and rarity hotspots in northern forests. Conserv Biol 18:1032-1042

Gjerde I, Sætersdal M, Rolstad J, Storaunet KO, Blom HH, Gundersen V, Heegaard E (2005) Productivitydiversity relationships for plants, bryophytes, lichens, and polypore fungi in six northern forest landscapes. Ecography 28:705-720

Gjerde I, Sætersdal M, Blom HH (2007) Complementary hotspot inventory-a method for identification of important areas for biodiversity at the forest stand level. Biol Conserv 137:549-557

Gjerde I, Grytnes J-A, Heegaard E, Sætersdal M, Tingstad L (2018) Red List updates and the robustness of sites selected for conservation of red-listed species. Glob Ecol Conserv 16:e00454

Gotelli NJ, Shimadzu H, Dornelas M, McGill B, Moyes F, Magurran AE (2017) Community-level regulation of temporal trends in biodiversity. Sci Adv 3:e1700315

Gustafsson L, De Jong J, Noréng M (1999) Evaluation of Swedish woodland key habitats using red-listed bryophytes and lichens. Biodivers Conserv 8:1101-1114

Gärdenfors U, Hilton-Taylor C, Mace GM, Rodriguez JP (2001) The application of IUCN Red List criteria at regional levels. Conserv Biol 15:1206-1212

Henle K, Bauch B, Auliya M, Külvik M, Pe'er G, Schmeller DS, Framstad E (2013) Priorities for biodiversity monitoring in Europe: a review of supranational policies and a novel scheme for integrative prioritization. Ecol Ind 33:5-18

Henriksen S, Hilmo O (2015) Norsk rødliste for arter 2015. Artsdatabanken, Norge

Hottola J, Siitonen J (2008) Significance of woodland key habitats for polypore diversity and red-listed species in boreal forests. Biodivers Conserv 17:2559-2577

Inger R, Gregory R, Duffy JP, Stott I, Vořišek P, Gaston KJ (2015) Common European birds are declining rapidly while less abundant species' numbers are rising. Ecol Lett 18:28-36

IUCN (2012) Red list categories and criteria version 3.1. Switzerland and Cambridge

IUCN (2016) The IUCN red list of threatened species version 2016-1 
Jansen F, Bonn A, Bowler DE, Bruelheide H, Eichenberg D (2019) Moderately common plants show highest relative losses. Conserv Lett. https://doi.org/10.1111/conl.12674

Kapfer J, Hédl R, Jurasinski G, Kopeckŷ M, Schei FH, Grytnes J-A (2017) Resurveying historical vegetation data-opportunities and challenges. Appl Veg Sci 20:164-171

Kirkpatrick JB (1983) An iterative method for establishing priorities for the selection of nature reserves: an example from Tasmania. Biol Conserv 25:127-134

Kukkula AS, Moilanen A (2013) Core concepts of spatial prioritisation in systematic conservation planning. Biol Rev 88:443-464

Lande R, Engen S, Sæther B-E (2003) Stochastic population dynamics in ecology and conservation. Oxford University Press Inc., New York

Latombe G, Richardson DM, Pysek P, Kucera T, Hui C (2018) Drivers of species turnover vary with species commonness for native and alien plants with different residence times. Ecology 99:2763-2775

Leathwick JR, Moilanen A, Ferrier S, Julian K (2010) Community-based conservation prioritization using a community classification, and its application to riverine ecosystems. Biol Conserv 143:984-991

Levandowski M, Winter D (1971) Distance between sets. Nature 234:34

Lindenmayer D, Pierson J, Barton P, Beger M, Branquinho C, Calhoun A, Caro T, Greig H, Gross J, Heino J, Hunter M (2015) A new framework for selecting environmental surrogates. Sci Total Environ 538:1029-1038

Lõhmus A, Runnel K (2018) Assigning indicator taxa based on assemblage patterns: beware of the effort and the objective. Biol Conserv 219:147-152

Maes WH, Fontaine M, Ronge K, Hermy M, Muys B (2011) A quantitative indicator framework for stand level evaluation and monitoring of environmentally sustainable forest management. Ecol Indic 11:468-479

Magurran AE, Baillie SR, Buckland ST, Dick JM, Elston DA, Scott EM, Smith RI, Somerfield PJ, Watt $\mathrm{AD}$ (2010) Long-term datasets in biodiversity research and monitoring: assessing change in ecological communities through time. Trends Ecol Evol 25:574-582

Magurran AE, Deacon AE, Moyes F, Shimadzu H, Dornelas M, Phillip DAT, Ramnarine IW (2018) Divergent biodiversity change within ecosystems. PNAS 115:1843-1847

Margules CR, Pressey RL (2000) Systematic conservation planning. Nature 405:243-253

Margules CR, Nicholls AO, Usher MB (1994) Apparent species turnover, probability of extinction and the selection of nature reserves: a case study of the Ingleborough limestone pavements. Conserv Biol 8:398-409

Martín-López B, González JA, Montes C (2011) The pitfall-trap of species conservation priority setting. Biodivers Conserv 20:663-682

McGill BJ, Nekola JC (2010) Mechanisms in macroecology: AWOL or purloined letter? Towards a pragmatic view of mechanism. Oikos 119:591-603

Melbourne BA, Hastings A (2008) Extinction risk depends strongly on factors contributing to stochasticity. Nature 454:100

Moilanen A (2012) Spatial conservation prioritization in data-poor areas of the world. Natureza Conservacao 10:12-19

Moilanen A, Wilson KA, Possingham HP (2009) Spatial conservation prioritization: quantitative methods and computational tools. Oxford University Press, Oxford

Morrison LW (2016) Observer error in vegetation surveys: a review. J Plant Ecol 9:367-379

Naidoo R, Balmford A, Ferraro PJ, Polasky S, Ricketts TH, Rouget M (2006) Integrating economic costs into conservation planning. Trends Ecol Evol 21:681-687

Nilsson IN, Nilsson SG (1985) Experimental estimates of census efficiency and pseudoturnover on islands: error trend and between-observer variation when recording vascular plants. J Ecol 73:65-70

Parody JM, Cuthbert FJ, Decker EH (2001) The effect of 50 years of landscape change on species richness and community composition. Glob Ecol Biogeogr 10:305-313

Possingham HP, Andelman SJ, Burgman MA, Medellin RA, Master LL, Keith DA (2002) Limits to the use of threatened species lists. Trends Ecol Evol 17:503-507

R Core Team (2019) R: a language and environment for statistical computing. R Core Team, R Foundation for statistical computing, Vienna, Austria

Ricketts TH, Dinerstein E, Boucher T et al (2005) Pinpointing and preventing imminent extinctions. Proc Natl Acad Sci USA 102:18497-18501

Rodrigues ASL, Gaston KJ (2002) Rarity and conservation planning across geopolitical units. Conserv Biol 16:674-682

Rodrigues ASL, Gregory RD, Gaston KJ (2000) Robustness of reserve selection procedures under temporal species turnover. Proc R Soc Lond Ser B Biol Sci 267:49-55 
Rodrigues ASL, Pilgrim JD, Lamoreux JF, Hoffmann M, Brooks TM (2006) The value of the IUCN Red List for conservation. Trends Ecol Evol 21:71-76

Rolstad J, Blanck Y-L, Storaunet KO (2017) Fire history in a western Fennoscandian boreal forest as influenced by human land use and climate. Ecol Monogr 87:219-245

Runge CA, Tulloch AIT, Possingham HP, Tulloch VJD, Fuller RA (2016) Incorporating dynamic distributions into spatial prioritization. Divers Distrib 22:332-343

Schmeller DS, Evans D, Lin Y-P, Henle K (2014) The national responsibility approach to setting conservation priorities-recommendations for its use. J Nat Conserv 22:349-357

Sverdrup-Thygeson A (2002) Key habitats in the Norwegian production forest: a case study. Scand J For Res 17:166-178

Tingstad L, Gjerde I, Dahlberg A, Grytnes JA (2017) The influence of spatial scales on Red List composition: forest species in Fennoscandia. Glob Ecol Conserv 11:247-297

Tulloch AIT, Chadès I, Dujardin Y, Westgate MJ, Lane PW, Lindenmayer D (2016) Dynamic species cooccurrence networks require dynamic biodiversity surrogates. Ecography 39:1185-1196

Verheyen K, Bažány M, Chećko E et al (2018) Observer and relocation errors matter in resurveys of historical vegetation plots. J Veg Sci 29:812-823

Virolainen KM, Virola T, Suhonen J, Kuitunen M, Lammi A, Siikamäki P (1999) Selecting networks of nature reserves: methods do affect the long-term outcome. Proc R Soc Lond Ser B Biol Sci 266:1141-1146

Watson JEM, Grantham HS, Wilson KA, Possingham HP (2011) Systematic conservation planning: past, present and future. In: Ladle RJ, Whittaker RJ (eds) Conservation biogeography. Wiley, Chichester, pp 136-160

Zobel M (1997) The relative role of species pools in determining plant species richness: an alternative explanation of species coexistence? Trends Ecol Evol 12:266-269

Publisher's Note Springer Nature remains neutral with regard to jurisdictional claims in published maps and institutional affiliations. 